\title{
Laparoscopic Spleen-Preserving No. 10 Lymph Node Dissection for Advanced Proximal Gastric Cancer Using a Left Approach
}

\author{
Chang-Ming Huang, MD, Qi-Yue Chen, MM, Jian-Xian Lin, MM, Chao-Hui Zheng, MM, Ping Li, MM, \\ Jian-Wei Xie, MM, Jia-Bin Wang, MM, Jun Lu, MM, and Xin-Tao Yang, MM \\ Department of Gastric Surgery, Fujian Medical University Union Hospital, Fuzhou, Fujian Province, China
}

\begin{abstract}
Background. We developed a novel procedure for spleenpreserving No. 10 lymph node (LN) dissection, which is difficult and advocates for patients with advanced proximal gastric cancer, except those with direct tumor extension to the spleen or definite LN metastasis at the splenic hilum. Methods. The surgeon reveals the splenic vessels (SVs), and the assistant pulls up the lymphatic fatty tissue on the surface of the lower lobar vessels of the spleen (LLVSs). The surgeon then exposes the left gastroepiploic vessels (LGEVs), completely separating the LLVSs from the LGEV roots. After tracking the SV termini, the No. 11d LNs are carefully dissected and the upper lobar vessels of the spleen are exposed from their roots to the upper pole of the spleen. During this process, 2-4 branches of the short gastric vessels are skeletonized and divided at their roots. The LNs behind the SVs in front of Gerota's fascia are then dissected. The above procedure was performed on 118 consecutive patients with stage cT2-3 disease.

Results. Mean operation time was $20.4 \pm 6.0 \mathrm{~min}$ (range 13-41 min), mean blood loss was $13.6 \pm 4.0 \mathrm{ml}$ (range $10-40 \mathrm{ml}$ ), and mean times to first flatus, fluid diet, and soft diet were $3.3 \pm 1.2$ days (range 2-8 days),
\end{abstract}

$4.8 \pm 1.6$ days (range $3-14$ days), and $8.1 \pm 4.1$ days (range 6-20 days), respectively. A mean $44.6 \pm 17.3 \mathrm{LNs}$ (range 22-103) were retrieved, including a mean $3.0 \pm 2.4$ (range 0-11) splenic hilar area LNs. At a median follow-up of 9 months, no patients had died or experienced recurrent or metastatic disease.

Conclusions. This procedure is feasible and simplifies complicated laparoscopic No. 10 LN dissection.

FINANCIAL DISCLOSURE Sponsored by National Key Clinical Specialty Discipline Construction program of China (No. [2012]649).

\section{REFERENCES}

1. Hyung WJ, Lim J-S, Song J, Choi SH, Noh SH. Laparoscopic spleen-preserving splenic hilar lymph node dissection during total gastrectomy for gastric cancer. J Am Coll Surg. 2008;207:e6-11.

2. Okabe H, Obama K, Kan T, Tanaka E, Itami A, Sakai Y. Medial approach for laparoscopic total gastrectomy with splenic lymph node dissection. J Am Coll Surg. 2010;211:e1-6.

3. Sakuramoto S, Kikuchi S, Futawatari N, Katada N, Moriya H, Hirai $\mathrm{K}$, et al. Laparoscopy-assisted pancreas- and spleenpreserving total gastrectomy for gastric cancer as compared with open total gastrectomy. Surg Endosc. 2009;23:2416-23.
Electronic supplementary material The online version of this article (doi:10.1245/s10434-014-3492-1) contains supplementary material, which is available to authorized users.

\section{(C) Society of Surgical Oncology 2014}

First Received: 26 October 2013;

Published Online: 4 March 2014

C.-M. Huang, MD

e-mail: hcmlr2002@163.com 